\title{
Breast Centers in Austria
}

\author{
Sabine Pöstlberger \\ Brust-Gesundheitszentrum, KH der Barmherzigen Schwestern Linz, Austria
}

\section{Key Words}

Breast Health Center - Collaborating Center .

Certification - Certification Commission .

Austrian Health Care Structure Plan · Quality

\section{Summary}

Breast centers (BRCs) in Austria are currently managed and will be managed in the future as interdisciplinary and largely virtual, well-structured entities. The goals of the initiative to set up these centers are convergence of care, enhancement of the quality of care delivered to women diagnosed with breast cancer, and a significant actual benefit for the affected women. Given the geographical and infrastructural circumstances and partly already existing diagnostic and therapeutic facilities, a collaborating center model seems to be the target-oriented solution to employ the already existing resources. Evaluation and optimization of outcome quality (i.e. overall survival rate, disease-free survival, breast conservation rate, etc.) necessitate the implementation of treatment pathways with data collection and recording in a central registry. The aim should be to create an independent 'neutral' certification commission (a standard setter) in order to adapt the requirements of BRCs to Austrian circumstances. An appointed certification agency reviews compliance with the specifications of the certification commission. The European Society of Mastology (EUSOMA) specifications, as laid down in the European Parliament, serve as guidelines. These specifications were compiled by the brain trust of the Austrian Federal Institute of Health (ÖBIG) in Chapter 3.6.11 'Breast Health Centers' for implementation in the Austrian Health Care Structure Plan (ÖSG). BRCs in Austria should demonstrate a minimum caseload of 100 primary diagnoses per year. The collaborating partners - the affiliated centers - may, however, join a BRC with a demonstrated minimum caseload of 30 per year. In this model, the outcome quality should be achieved even with a smaller caseload with structure quality assurance. It is planned that, by the end of 2016, breast health centers will take over the comprehensive care of breast cancer patients nationwide. Center certification is viewed as quality enhancement since care is provided to all patients on a verifiable high quality level, subject to constant improvements.

\author{
Schlüsselwörter \\ Brustgesundheitszentrum · Kooperierendes Zentrum . \\ Zertifizierung · Zertifizierungskommission . \\ Österreichischer Strukturplan Gesundheit (ÖSG) · Qualität
}

\section{Zusammenfassung}

Brustzentren (BRZ) in Österreich sind und werden künftig als interdisziplinäre, zum Großteil als virtuelle, gut strukturierte Einheiten geführt. Ziele der Zentrumsbildung sind die Konzentration der Versorgung, die Stärkung der Qualität der Versorgung der Frauen mit der Diagnose Mammakarzinom und ein spürbarer Benefit für die betroffenen Frauen. Durch geographische und infrastrukturelle Gegebenheiten und die zum Teil schon vorhandenen diagnostischen und therapeutischen Einrichtungen ist ein kooperatives Zentrumsmodell für die Nutzung der bereits vorhandenen Ressourcen eine zielgerichtete Lösung. Zur Evaluierung und Optimierung der Ergebnisqualität (Gesamtüberleben, rezidivfreies Überleben, Brusterhaltungsrate, usw.) ist die Implementierung von Behandlungspfaden mit Erfassung der Daten in einem zentralen Register erforderlich. Die Schaffung einer unabhängigen "neutralen" Zertifizierungskommission (Normengeber) ist anzustreben, um die Anforderungen der BRZ an österreichische Verhältnisse anzupassen. Eine beauftragte Zertifizierungsgesellschaft überprüft die Konformität mit den Vorgaben der Zertifizierungskommission. Als Vorlage dienen die Anforderungen der EUSOMA (European Society of Mastology), wie im Europaparlament festgelegt. Diese Vorgaben wurden vom Österreichischen Bundesinstitut für Gesundheit (ÖBIG) in einem Expertengremium im Kapitel 3.6.11 "Brustgesundheitszentren» zur Implementierung in den Österreichischen Strukturplan Gesundheit (ÖSG) erstellt. BRZ sollen in Österreich eine Mindestfallzahl von 100 Primärdiagnosen pro Jahr aufweisen. Kooperierende Partner, affiliierte Zentren, können sich ab einer Fallzahl von mindestens 30 pro Jahr an ein BRZ anschließen. In diesem Modell soll es gelingen, die Ergebnisqualität auch mit einer kleineren Fallzahl mit sehr guten Strukturen zu erzielen. Bis 2016 ist die Umsetzung der flächendeckenden Versorgung der Mammakarzinompatientinnen in Brustgesundheitszentren geplant. Die Zertifizierung von BRZ bedeutet Qualitätsgewinn, da die Behandlungsqualität für alle Patientinnen auf überprüfbarem hohem Niveau gewährleistet ist und laufend verbessert wird.

\begin{tabular}{ll}
\hline KARGER & ๑ 2009 S. Karger GmbH, Freiburg \\
Fax +497614520714 & $\begin{array}{l}\text { Accessible online at: } \\
\text { www.karger.com/brc } \\
\text { Information@Karger.de } \\
\text { www.karger.com }\end{array}$
\end{tabular}




\section{Introduction}

The European Parliament's motion for a resolution on breast cancer in the enlarged European Union (EU) [1] (Strasbourg, France, October 2006) serves as the basis for the creation of breast centers (BRCs) in Austria to provide comprehensive care to breast cancer patients nationwide. The EU member states have been prompted to achieve an up to $35 \%$ reduction in breast cancer mortality. The position paper 'The Requirements of a Specialist Breast Unit' by R. W. Blamey and L. Cataliotti on behalf of the European Society of Mastology (EUSOMA; position paper published in 2000 [2], revised in 2004) describes the basic requirements for BRCs and for the EU's motion for a resolution.

\section{Implementation of Breast Health Centers - the Political Background in Austria}

The Austrian Health Care Structure Plan (Österreichischer Strukturplan Gesundheit, ÖSG) is the binding basis for an integrated planning of the national healthcare delivery structure in Austria. The ÖSG sets the general framework for detailed planning on the regional level, especially for the Regional Health Care Structure Plans (Regionale Strukturpläne Ge- sundheit, RSG) in the states. The Federal Health Commission (Bundesgesundheitskommission) approved the first edition of the ÖSG 2006 in December 2005, while in the beginning of March 2009, a revised version of the ÖSG 2008 emerged [3]. The ÖSG 2008 was supplemented by a number of amending chapters. Due to incompleteness at the time, Chapter 3.6.11 ('Breast Health Centers') was not yet included in the structure plan.

The Austrian brain trust, a cross-disciplinary team of professionals, was mandated with the task of setting a planning benchmark and minimum caseload requirements for BRCs in Austria, as well as to formulate Chapter 3.6.11 'Breast Health Centers' for incorporation into the Austrian Health Care Structure Plan (ÖSG).

\section{The Basis for Minimum Caseload Formulation}

In order to set up a nationwide comprehensive care system with certified breast health centers in Austria, the EUSOMA criteria stipulate the frequency of 1 BRC per $>250,000$ inhabitants, with 150 primary cases per year. In the case of Austria, this means setting up 30 BRCs. Figure 1 displays the spatial distribution of the currently operating hospitals with the number of breast cancer cases per year. The possible distribu-
Fig. 1. Hospital frequency (kindly provided by ÖBIG, Dr. Gerhard Fülöp).
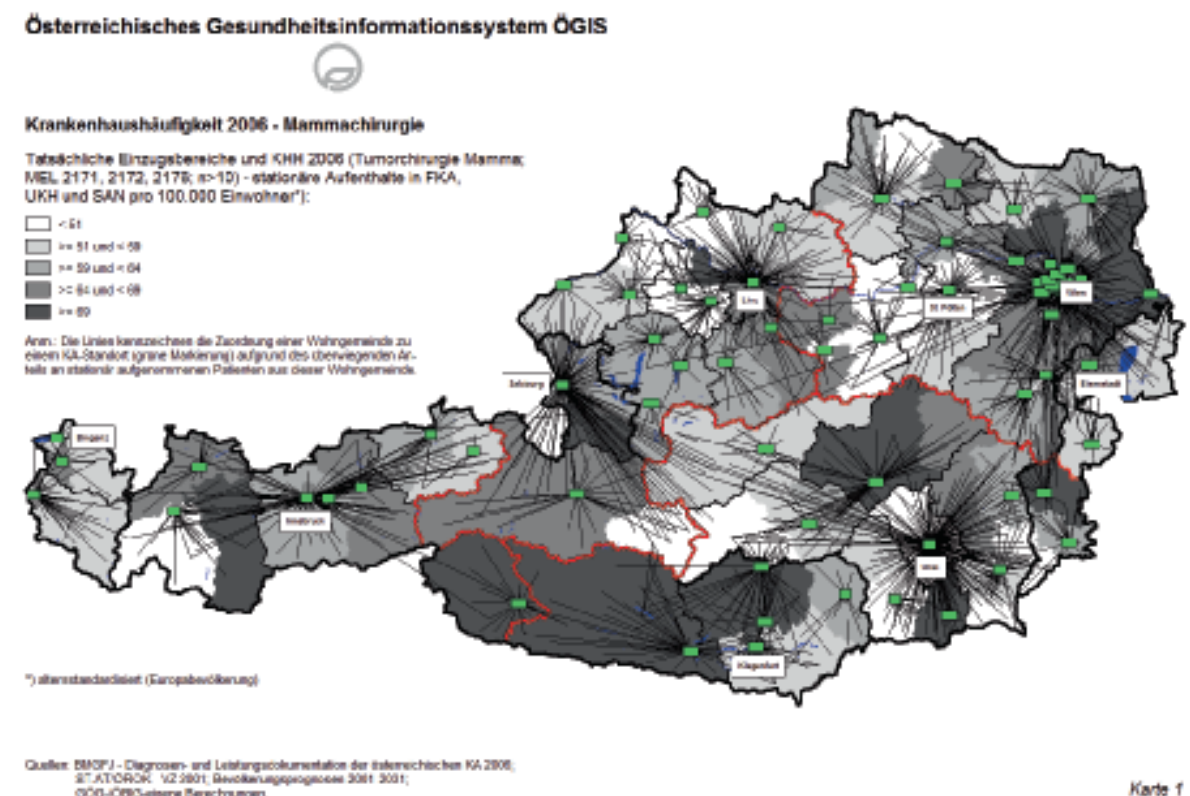

Fig. 2. Collaboration model (kindly provided by ÖBIG, Dr. Barbara Schleicher). Certified Breast Health Center: Pathology, radio-oncology, medical oncology, radiology, nuclear medicine, surgery $(\mathrm{OB} / \mathrm{GYN})$; Affiliated Partners: diagnostics, surgery.
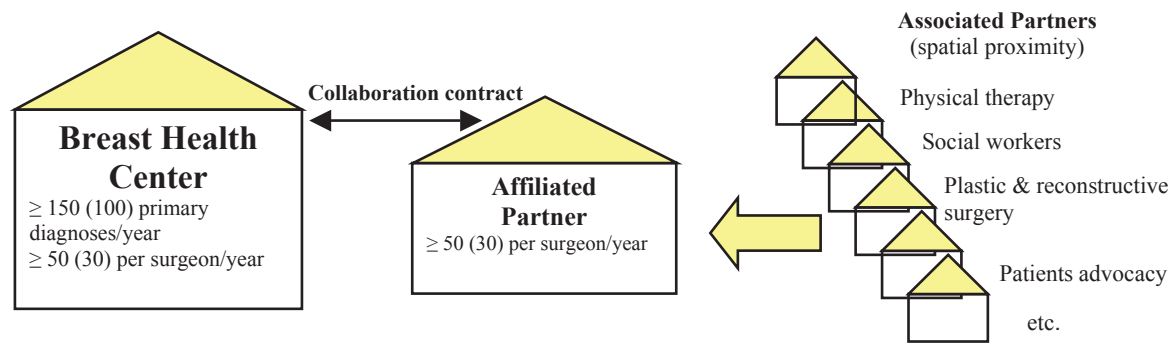
tion of future breast health centers is shown in terms of these catchment areas. The goal is centralization with professional focus on interdisciplinary teamwork.

The different health care systems and administrative health care sectors in individual European countries often cannot allow for an exact assimilation of the EUSOMA standards (150 primary cases, 50 surgical procedures per surgeon). Given the geographical health care delivery structure in Austria, an adjusted 'modified' model - the collaboration model with 'affiliated centers' - should be adopted (fig. 2). For breast health centers, the brain trust has set the minimum caseload requirement to 100 primary cases per year, and for collaborating affiliated partners (AP) to 30 cases per year. Chapter 3.6.11 defines infrastructural prerequisites for both center types. Departments with less than 30 primary cases per year should in the future refer their patients to departments with a higher caseload and adequate infrastructure.

\section{The Benefits of 'Certified' Breast Health Centers}

- Structural elements: optimized treatment chain, regular process evaluation and compliance, firm commitment to the quality management system, audits, benchmarking, spatial and temporal adjustments of the entire treatment chain (patient pathways).

- Medical aspects: mortality reduction, improvement of patient survival and quality of life, lowering the frequency of follow-up resections and recurrences, quality-supported guidelines, interdisciplinary team of experts, continuing education.

- Business aspects: cost-containment by way of synergies in continuing education, technical endowment, resource utilization (e.g. surgical capacities), a more cost-efficient demand planning and an optimized human resource planning. On March 28, 2007, the 'BRC brain trust' resolved on the setup of breast health centers according to the EUSOMA model in Austria by the year 2016.

\section{Specifications of the Austrian Health Institute (ÖBIG)}

Austrian Health Institute (Österreichisches Bundesinstitut für Gesundheit) specifications for breast health centers, final version (March 28, 2007) (Chapter 3.6.11) [4]:

\section{A. Definitions, Target Groups}

\section{Goals and Conceptual Design}

- Collaboration, convergence and standardization of breast cancer care

- Optimization of operational procedures of the entire treatment chain, from diagnostics and therapy to follow-up care, along with concurrent improvements in interdisciplinary teamwork and communication [strategies]

- Increase in treatment safety with concurrent risk management

- Setting up of a disease management program

\section{Target Group}

Individuals with benign and malignant breast tumors (ICD-10 C50.x, D24.x; MEL 2171, 2172, 2176, 2177)

Content

- Convergence and centralization of core services in certified BRC

- Compliance with qualitative and quantitative diagnostic and therapeutic standards according to the European Guidelines for Quality Assurance in Breast Cancer Screening and Diagnosis, 2006

\section{B. Structure of Care Provision}

\section{Two Types of BRC}

A certified BRC provides all core services (diagnostics, therapy and follow-up) independently and must demonstrate compliance with the minimum caseload requirements set to 150 per BRC and 50 per surgeon per year (modified on $11 / 9 / 2008$ to 100 and 30 , respectively). Breast health centers may cooperate with hospital departments. The 'affiliated partners' (AP) offer partial services such as diagnostics, surgery and inpatient care. To qualify, an AP must demonstrate at least 50 (30) breast cancer cases per surgeon per year. BRC and AP should enter into a contractual relationship which should be reviewed for relevance by the BRC on a yearly basis.

\section{BRC Quality Criteria}

Uniform quality criteria:

- Interdisciplinary team

- The BRC's core service offerings such as imaging diagnostics, surgical procedures, radiation therapy, pathology and medical oncology

- Availability of additional services such as physical therapy, psycho-oncology, plastic and reconstructive surgery as well as genetic counseling

\section{Quality Criteria for BRC and AP}

Interdisciplinary teamwork in the course of the weekly Tumor Board meeting

- Review of all breast cancer cases in pre- and post-operative conference meetings

- Obligatory attendance of the interdisciplinary specialist conferences (surgery or obstetrics/gynecology (OB/GYN), radiology, medical oncology, radio-oncology and pathology)

- Counseling, joint therapy formulation and administration 
- Cross-organizational and cross-sectoral collaboration between various professions

Quality management

- Organizationally uniform quality management system according to EUSOMA

- Implementation of a uniform data collection system

- Continuous measurement and analysis of relevant quality indicators in all functional units

- Creation of quality reports detailing the scope of activities, quality objectives, quality and resource planning, implementation and outcomes of quality-related measures, audit reports according to EUSOMA

Patient care

- Systematic and comprehensive information on the affected individuals

- Providing opportunity to participate in clinical trials and research projects

- Involvement of all affected individuals in the therapeutic decision-making process ('informed consent')

- Psychosocial support and counseling

- Cooperation with patient support groups

Quality Criteria for AP

Uniform quality criteria:

- Interdisciplinary team

- Provision of at least the following core services: diagnostics and surgical procedures (radiology, surgery/gynecology, pathology)

- Ensuring the provision of core services such as radiation therapy, medical oncology and the like within the collaborating breast health center

\section{Planning}

Estimate of demand: 1 BRC per at least 250,000 inhabitants. - BRC

- Minimum yearly requirement of at least 150 (100) newly diagnosed breast cancer cases per BRC as well as 50 surgeries on patients with newly diagnosed breast cancer per surgeon and gynecologist.

- Each BRC should have a maximum of 2 affiliated breast surgery collaborating centers.

- AP

- Under certain specified circumstances, hospital departments that diagnose at least 50 (30) new breast cancer cases yearly and carry out at least 50 primary cancer surgeries on these patients per [board-certified] surgeon or gynecologist may be affiliated with the nearest BRC. A detailed quality control and review of the AP must precede each collaboration; in addition, the BRC must carry out yearly quality audits. A prerequisite for affiliation is compliance with the European Guidelines for Quality Assurance in Breast Cancer Screening and Diagnosis (2006).
The BRC will coordinate and oversee the AP's compliance with these EU guidelines; specifically, the BRC should carry out regular evaluations of the AP within the context of Tumor Board meetings. Further particulars are set forth in the collaboration agreement (guidelines for treatment modalities, obligatory attendance of tumor conferences, cancer documentation, etc.)

Planning Targets by the Year 2016

- By 2010: $50 \%$ of all breast cancer patients treated in certified $\mathrm{BRC}$

- By 2013: 75\% of all breast cancer patients treated in certified BRC

- By 2016: all breast cancer patients nationwide treated in certified BRC

(Reference: EU Parliament Decision of October 25, 2006)

\section{Personnel Structure and Qualification}

\section{BRC Personnel Structure and Qualification}

Core team (minimum requirements based on 150 (100) newly diagnosed breast cancer cases):

- 2 physicians ( $\mathrm{m} / \mathrm{f})$ with board certification in surgery or $\mathrm{OB} /$ GYN with specialized knowledge/skills in breast care

- 1 [internal] medicine specialist $(\mathrm{m} / \mathrm{f})$ with board certification in hematology/oncology

- 2 board-certified radiologists $(\mathrm{m} / \mathrm{f})$ with expert knowledge/ skills in breast diagnostics

- 1 board-certified pathology specialist $(\mathrm{m} / \mathrm{f})$ with particular knowledge/skills in breast pathology

- 1 board-certified radio-oncologist (m/f) with expert knowledge/skills in breast cancer radiotherapy

- 1 expert radiation technologist (RT) (m/f) for diagnostic purposes

- 2 registered nurses and technicians, specially trained for the care of patients diagnosed with diseases of the breast ('breast care nurse')

- 1 data manager $(\mathrm{m} / \mathrm{f})$

Minimum caseload:

- Operating on 50 (30) newly diagnosed breast cancer patients per physician with board certification in surgery or OB/GYN

- Pathology, radio-oncology and medical oncology: 50 cases per physician in each category yearly

- Radiology: 1000 mammography procedures, 30 breast ultrasounds and 30 percutaneous biopsies performed on a yearly basis per physician; 200 breast magnetic resonance images (MRIs) yearly per physician

\section{Personnel Structure and Qualification for BRC and AP}

Collaboration with professionals from the following professions: nuclear medicine, psycho-oncology, physical therapy, plastic and reconstructive surgery, social workers, pastors. Qualification: EU guidelines for core team qualification. 
Table 1. Infrastructural requirements

\begin{tabular}{lll}
\hline Complete medical-technical equipment allowing for & \multicolumn{2}{l}{ Availability as per quality criteria } \\
\cline { 2 - 3 } a complete and appropriate diagnosis & Breast center & Affiliated partner \\
\hline Mammography device and stereotactic unit & HC & HC \\
Ultrasound device & HC & HC \\
Magnetic resonance and stereotactic unit & HC & available in BRC \\
Preoperative core needle biopsy & HC & HC \\
Nuclear medicine diagnostic tests & HC & SP \\
Scintigraphy device (Sentinel) & HC & HC \\
Histology, immunohistochemistry, receptor & HC & SP \\
$\quad$ determination, cytology, immunocytology, & & \\
$\quad$ molecular biology & & HC \\
Intraoperative frozen-section study & SP & HC \\
Molecular genetics studies & HC & SP \\
Genetic counseling & HC & available in BRC \\
Tumor marker diagnostics (incl. general & & HC \\
$\quad$ laboratory) & HC & SP \\
Diagnostics of infections & SP & SP \\
Blood reservoir or transfusion facilities/ & & \\
$\quad$ equipment & HC & SP \\
Preparation of cytostatics & SP & SP \\
Palliative ward & HC & SP \\
Oncology day-clinic & HC & HC \\
Patient monitoring unit & HC & HC \\
Information and communication technologies & & \\
\hline HC, Hospital complex; SP, spatial proximity. & &
\end{tabular}

\section{AP Personnel Structure and Qualification (On-Site if Available)}

Core team (minimum requirements based on 50 (30) newly

diagnosed breast cancer cases):

- 1 physician $(\mathrm{m} / \mathrm{f})$ with board certification in surgery or $\mathrm{OB} /$ GYN with specialized knowledge/skills in breast care

- 1 [internal] medicine specialist $(\mathrm{m} / \mathrm{f})$ with board certification in hematology/oncology

- 1 board-certified radiologist $(\mathrm{m} / \mathrm{f})$ with expert knowledge/ skills in breast diagnostics

- 1 board-certified pathology specialist (m/f) with particular knowledge/skills in breast pathology

- 1 board-certified radio-oncologist (m/f) with expert knowledge/skills in breast cancer radiotherapy

- 1 expert radiation technologist (RT) (m/f) for diagnostic purposes

- 1 registered nurse/technician, specially trained for the care of patients diagnosed with diseases of the breast ('breast care nurse')

- 1 data manager $(\mathrm{m} / \mathrm{f})$

\section{E. Infrastructural Requirements}

The infrastructural requirements are outlined in table 1 . Due to changes introduced to the minimum caseload requirements on November 13, 2008, this decision could not yet be incorpo- rated in the ÖSG as the final version. In the above-mentioned chapter initially drawn up (2007), the minimum caseload requirements have not yet been corrected.

BRC in Austria should demonstrate a caseload of at least 100 primary diagnoses per year. However, the collaborating partners - the affiliated centers - can join a breast health center (BRC) with the proven statistics of a minimum of 30 cases per year. This very significant change has not yet been taken into account in the above-mentioned chapter. Due to the lack of bibliography data, the Surgical Society has thus obtained a chance to demonstrate by the year of 2016 that a positive outcome quality is not guaranteed by case statistics alone. Should we fail to prove this hypothesis, the caseload requirements of $150 / 50$ shall be introduced as the stipulated guidelines from 2016 onwards.

\section{Next Steps}

- Approval of the modified Chapter 3.6.11 by the Federal Health Commission (modified caseload)

- Implementation in the ÖSG and the regional structure plans (RSG)

- Appointment of an Austrian Certification Commission (GÖG/ÖBIG)

- Nomination of each member of the Certification Commission by the brain trust 
- Establishment of a certification procedure - creation/modification of DOC-CERT's specification of requirements based on the ÖSG's 'Breast Health Centers' concept

- Setting up of a central data registry

- Education and training of expert consultants (experts from all professional fields)

\section{Goals of Certification}

- Quality enhancement due to data transparency (external/internal), strengthening of interdisciplinary approaches and improved networking

- Continuous monitoring/optimization of procedural and outcome quality, improved image, improved caseload statistics

$=$ Certification results in improved quality, as the treatment is delivered at a verifiable high quality level, subject to constant improvement

\section{Primary Certification Goals}

- Convergence of care

- Improvement in the quality of care via a treatment pathway

- The patient should feel the benefit

\section{Assessment}

The evaluation of certified breast centers should not focus exclusively on the frequency of surgical procedures.

Improvement of the internal operational processes, professional qualification of the entire team as well as establishment of patient pathways and improvement of treatment outcomes are equally important.

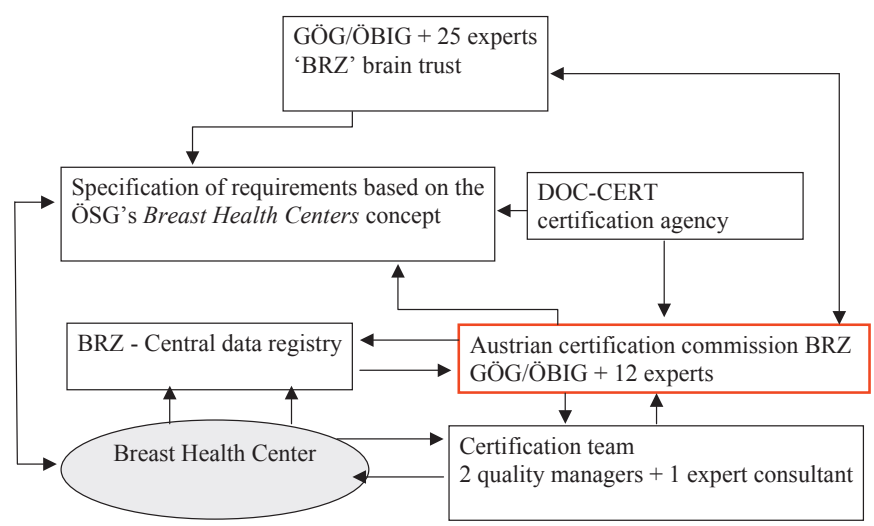

Fig. 3. Certification system (kindly provided by ÖBIG, Dr. Barbara Schleicher).

\section{Certification}

Certification is assessment of conformity (fig. 3). A certification agency assesses specifications of the certification commission (the standard setter). It is assessed whether the center has implemented the specified standards and whether the center is applying these standards to its daily operations.

The standards themselves are not verified as this is not the certification procedure's mission but rather that of the standard setter, i.e. GÖG/ÖBIG, professional associations, state representatives, etc.

\section{Conflict of Interest}

The authors did not provide a conflict of interest statement.

\section{References}

1 Entschließung des Europäischen Parlaments zu Brustkrebs (2002/2279(INI))

2 Blamey RW, Cataliotti L, on behalf of EUSOMA: The requirements of a specialist Breast Unit EUSOMA. Eur J Cancer 2000;36:2288-2293.
3 Österreichsicher Strukturplan Gesundheit ÖSG: Bundesministerium für Gesundheit, verfasst von Gesundheit Österreich GmbH GÖG/ÖBIG (Österreichisches Bundesinstitut für Gesundheit).
4 ÖBIG: Kapitel 3.6.11 Brustgesundheitszentren - Expertenbeschluss: 28.3.07 